\title{
Economic growth and methane emission: testing the EKC hypothesis in ASEAN economies
}

Economic growth and methane emission

\author{
Rana Muhammad Adeel-Farooq \\ Department of Economics, University of Sahiwal, Sahiwal, Pakistan \\ Jimoh Olajide Raji \\ Department of Finance, SEFB, Universiti Utara Malaysia, Sintok, Malaysia, and \\ Bosede Ngozi Adeleye \\ Department of Economics and Development Studies, Covenant University, \\ Ota, Nigeria
}

\begin{abstract}
Purpose - The purpose of this study is to analyze the Environmental Kuznets Curve (EKC) hypothesis within the methane $\left(\mathrm{CH}_{4}\right)$ emission-economic growth nexus among the six Association of Southeast Asian Nations (ASEAN) countries from 1985 to 2012.

Design/methodology/approach - The study employs dynamic panel data estimation approaches such as mean group (MG) and pooled MG (PMG) techniques.

Findings - The findings reveal that the EKC hypothesis for the $\mathrm{CH}_{4}$ emission in these economies proves to be valid. In other words, economic growth causes $\mathrm{CH}_{4}$ emissions to decrease. Nevertheless, energy consumption is deteriorating the environment by enhancing $\mathrm{CH}_{4}$ emissions in these countries.

Originality/value - The ASEAN region has experienced substantial economic growth over the previous few decades. Nevertheless, pollution has also increased manifolds in this region. Methane is a more potent greenhouse gas (GHG) as compared to carbon dioxide $\left(\mathrm{CO}_{2}\right)$ and a major source of socio-economic issues in the ASEAN region. This study is the first in the existing literature on the EKC hypothesis examining the role of economic growth on $\mathrm{CH}_{4}$ emissions in the selected ASEAN countries. The outcomes of this study could be really beneficial for the policymakers in this region regarding sustainability and economic development.
\end{abstract}

Keywords Methane emission, Economic growth, EKC, ASEAN, PMG, MG

Paper type Research paper

\section{Introduction}

The Club of Rome (1972) stated that economic growth is detrimental to the natural environment, and the world ahead will crumble as the limits of non-renewable resources, agricultural yields and the capacity to absorb hazardous pollutants will be reached soon (Meadows et al., 1972). Besides, the Intergovernmental Panel on Climate Change (IPCC) argued that anthropogenic and enhanced economic activities are responsible for the rampant natural environment decay across the globe (IPCC, 2014). In the same way, the United Nations Environment Program (UNEP) noted that the world due to over-exploitation of natural resources is following unsustainable growth paths, experiencing a substantial loss of biodiversity and a decrease in human welfare (UNEP, 2019). Nonetheless, the Sustainable Development Goals (SDGs) of the UN encourage countries to formulate policies to spur the pace of economic growth and preserve the natural environment simultaneously. Therefore, sustainability and economic development have emerged as a gigantic challenge for the researchers and policymakers these days.

In the literature, the relationship between economic growth and environmental degradation is well explained by the renowned Environmental Kuznets Curve (EKC)

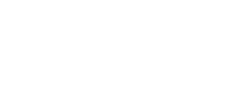


hypothesis. The EKC hypothesis as surmised by Grossman and Krueger (1991) demonstrates that per capita economic growth and pollution exhibits a non-linear relationship. That is, pollution increases with an increase in per capita income; it reaches a maximum level and begins to decrease as the income level increases.

Economic growth, according to Grossman and Krueger (1991), influences the environment by technique, composition and scale effects. By scale effect, economic growth increases the scale of production, which eventually enhances pollution levels and deteriorates the natural environment. The composition effect characterizes a situation when an economy in the process of growth alters its structure from agriculture to industry, leading to an increase in pollution. Nonetheless, pollution begins to decrease as the economy further shifts towards the services, and light manufacturing sectors experience an increased growth rate. The technique effect, on the other hand, denotes the replacement of obsolete production technique and equipment with the advanced and efficient one, which mitigates the intensity of pollution. Additionally, the EKC hypothesis' enthusiasts argue in support that economic growth, in the long run, enhances the quality of the environment by providing green and energy-efficient technologies, creating awareness about environmental issues and investing additional per capita expenditures on the environment (Panayotou, 1993; Stern, 1998; Beckerman, 1992). Moreover, the World Bank (IBRD) in its report "Development and the environment" also endorsed the EKC hypothesis by arguing that "The view that greater economic activity inevitably hurts the environment is based on static assumptions about technology, tastes and environmental investments' and that: 'As incomes rise, the demand for improvements in environmental quality will increase, as will the resources available for investment" (IBRD, 1992). Additionally, Beckerman (1992) has also asserted that economic development, in the long run, enhances environmental quality.

The per capita income and pollution nexus (the $\mathrm{EKC}$ ) in the existing literature has been examined by various researchers through the employment of different and havoc pollutants. For example, few studies (Borhan et al., 2018; Jalil and Mahmud, 2009; Saeidpour et al., 2015; Shahbaz et al., 2019; Nasir et al., 2019) used $\mathrm{CO}_{2}$ emissions to examine the validity of the EKC hypothesis. Whereas, Al-Mulali et al. (2015a, b) tested the EKC for ecological footprints; Cole (2004) used ten different air and water quality indicators; Panayotou (1993) and Bhattarai and Hammig (2001) employed deforestation and Grossman and Krueger (1991) used smoke and sulphur dioxide to empirically examine the validity of the EKC hypothesis. Besides, various other studies have endeavoured to unveil the EKC hypothesis. Nevertheless, to date, the outcomes of these studies are not conclusive. For instance, some studies (see, for instance, Al-Mulali et al., 2016; Baek, 2015; Bilgili et al., 2016; Nasir et al., 2019; Shahbaz et al., 2019) discovered empirical evidence corroborating the EKC hypothesis. On the other hand, the literature contains studies (see, for instance, Amri, 2018; Kisswani et al., 2018; Saboori et al., 2012; Saboori et al., 2012) which have not observed evidence supporting the inverted U-shaped relationship between economic growth and pollution. These mixed findings and the use of distinct pollutants indicate to test the EKC hypothesis further by employing some other detrimental pollutants responsible for rapid climate change such as methane $\left(\mathrm{CH}_{4}\right)$ emissions. The extensive review of the EKC literature by authors reveals that the $\mathrm{CH}_{4}$ emission has not been given required and considerable attention from the researchers. As a matter of fact, $\mathrm{CH}_{4}$ is more potent and havoc emission for the humans and other living species than the other extensively employed pollutants such as carbon dioxide $\left(\mathrm{CO}_{2}\right)$ and sulphur dioxide emissions in the domain of economic growth-pollution literature. This accentuates a research gap in the EKC literature and an empirical investigation examining the economic growth- $\mathrm{CH}_{4}$ emission nexus is, therefore, inevitable. Hence, this study endeavours to fill this gap by testing the EKC hypothesis in the selected six economies of Association of Southeast Asian Nations (hereafter ASEAN), namely Indonesia, Malaysia, Philippines, Singapore, Thailand and Vietnam. Moreover, the following are the contributions of the current study to the existing literature concerning the EKC hypothesis: 
First, this study tests the EKC hypothesis using $\mathrm{CH}_{4}$ emission as a pollutant unlike the previous studies (Kisswani et al., 2018; Liu et al., 2017; Saboori et al., 2012; Nasir et al., 2019; Phong, 2019; Shahbaz et al., 2019), which have tested the EKC hypothesis in ASEAN region using the $\mathrm{CO}_{2}$ emission. According to our knowledge, no study till date has examined the association between economic growth and $\mathrm{CH}_{4}$ emission within the framework of the EKC hypothesis in the ASEAN countries. $\mathrm{CH}_{4}$ is a greenhouse gas $(\mathrm{GHG})$ like $\mathrm{CO}_{2}$, which is equally responsible for climate change and a more potent $\mathrm{GHG}$ than $\mathrm{CO}_{2}$. It accounts for $20 \%$ of the total GHGs in the atmosphere. Moreover, anthropogenic and natural activities are the major sources of $\mathrm{CH}_{4}$ emission. However, the $50-65 \% \mathrm{CH}_{4}$ emission is attributed to the anthropogenic activities (Janardanan et al., 2017). In recent times, as a consequence of production, increased agricultural activities (to feed the growing population) and combustion of the fossil fuels, the level of $\mathrm{CH}_{4}$ emissions have increased severely in the atmosphere causing multi-dimensional challenges for the environment (Yusuf et al., 2012).

Second, it contributes to the existing EKC literature by investigating the economic growth and $\mathrm{CH}_{4}$ emission nexus through employing the dynamic panel data estimation techniques such as mean group (MG) and pooled mean group (PMG) estimators. These estimation techniques have certain advantages over the traditional panel data analysis techniques, which are discussed in the methodology section of this study. Therefore, the outcomes of the study are likely to be robust and valuable for the policymakers of these ASEAN countries.

Third, this study specifically focuses on the six countries of the ASEAN region. The literature on the EKC indicates that there are few studies which have tested the EKC hypothesis for the six ASEAN countries (namely Indonesia, Malaysia, Philippines, Singapore, Thailand and Vietnam). According to the Asian Development Bank (2015), these six countries are responsible for $90 \%$ of the total GHG emissions in the region. Moreover, according to a recent report of IMF, these ASEAN countries are vulnerable to climate change. In particular, as a consequence of the climate change the rice yields in Indonesia, Vietnam, Thailand and the Philippines are expected to drop by $50 \%$. They are anticipated to face severe droughts, deluges and extreme food insecurity if suitable and immediate policies to reduce GHG are not implemented (ADB, 2015; Prakash, 2018). Additionally, the studies on the EKC hypothesis in ASEAN countries have not tested the EKC hypothesis for the $\mathrm{CH}_{4}$ emission. These six ASEAN countries have experienced considerable economic growth over the previous few decades, and the $\mathrm{CH}_{4}$ emission is also rampant here. To support the argument of this study, Figure 1 and Figure 2 show the trend of economic growth and $\mathrm{CH}_{4}$ emission across the six ASEAN countries.

\section{Literature review and stylized facts}

The EKC hypothesis in the existing literature has been tested with the use of different pollutants. For instance, the extensively employed pollutants in the economic growthpollution nexus are $\mathrm{CO}_{2}, \mathrm{SO}_{2}$, ecological footprints, deforestation and water quality (Jalil and Mahmud, 2009; Nasir et al., 2019; Panayotou, 1993; Grossman and Krueger, 1991). Nevertheless, as a result of different pollutant and distinct estimation methods, the outcomes of these studies proved to be inconclusive.

For panel data studies, using the fully modified ordinary least squares (FMOLS) technique, Nasir et al. (2019) analyzed the growth- $\mathrm{CO}_{2}$ emissions relationship in the selected ASEAN countries from 1982 to 2014 . Their findings revealed an inverted U-shape association in the long run. Likewise, Phong (2019) examined a similar relationship among the selected ASEAN countries from 1971 to 2014 and found that at initial stages of economic growth, $\mathrm{CO}_{2}$ increases but starts to decrease as these countries achieve more economic development. Similarly, Al-Mulali et al. (2015a, b) concluded that the EKC hypothesis has not held for lowincome countries but countries with high and middle-income. In another study, Bilgili et al.,

\author{
Economic \\ growth and \\ methane \\ emission
}


MEQ

Figure 1.

Trend of economic growth in the selected ASEAN countries
Figure 2.

Methane emission (Kt of $\mathrm{CO}_{2}$ equivalent)
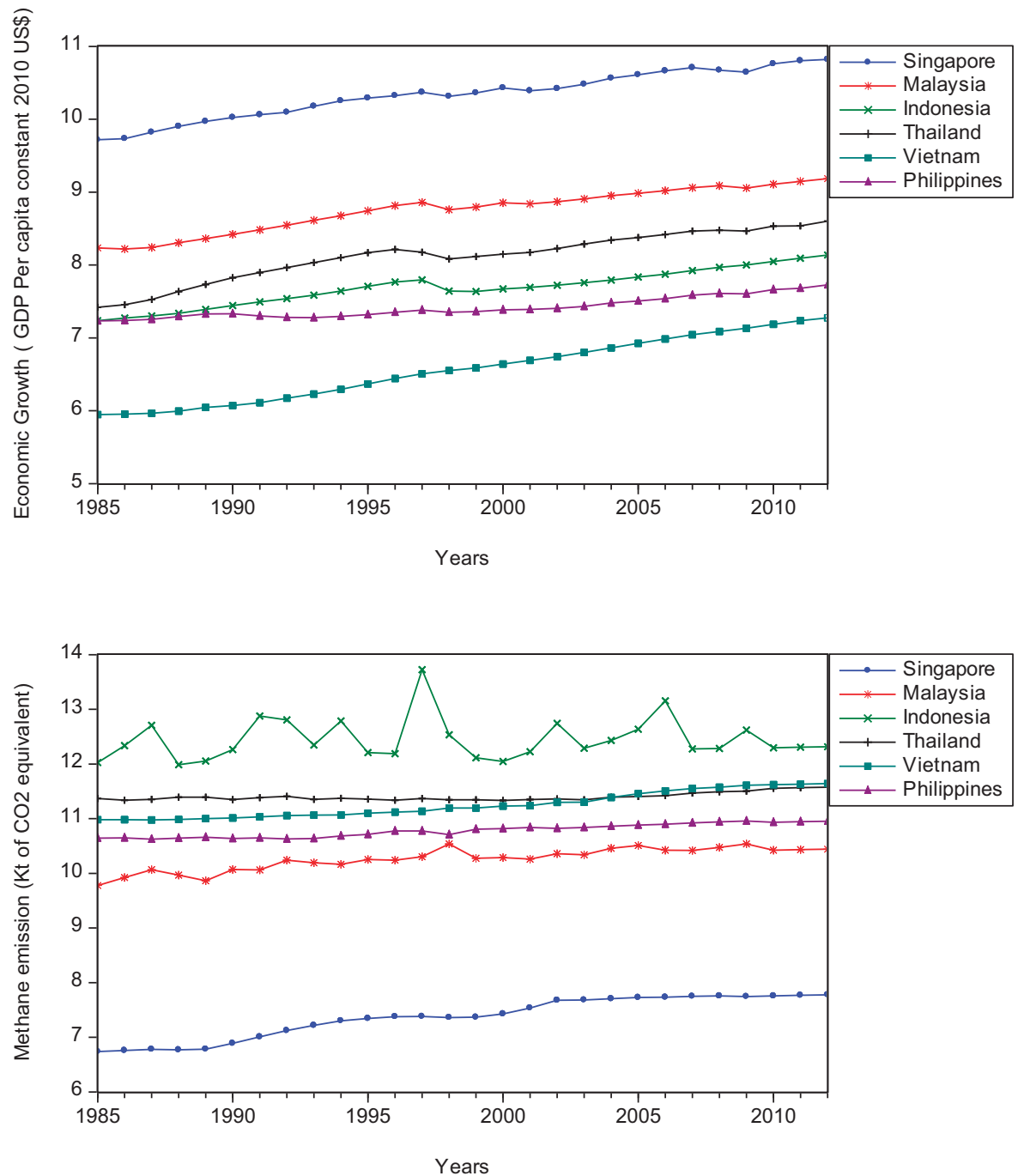

2016 estimated the impact of gross domestic product (GDP) and its quadratic form on the environmental pollution measured by the $\mathrm{CO}_{2}$ emissions in the Organisation for Economic Co-operation and Development (OECD) countries from 1977 to 2010. Their findings discovered that economic growth deteriorated the environmental quality initially but began to ameliorate after substantial economic growth was attained. This outcome exhibited to have the EKC hypothesis in these countries. Likewise, López-Menéndez et al. (2014) measured the EKC hypothesis in European countries during the 1996-2010 period using fixed and random effect techniques. The outcomes of the study supported the EKC hypothesis. Similarly, Zoundi (2017) attempted to measure the non-linear influences of economic growth on the $\mathrm{CO}_{2}$ emissions in selected African countries over the 1980-2012 period. The study employed a panel cointegration method and examined the robustness of the outcomes by 
various advanced panel estimation methods. The EKC hypothesis was discovered to be valid in these selected African countries over the specified period.

For time series analysis, Shahbaz et al. (2019) in the context of Vietnam, from 1974 to 2016, found the existence of the EKC hypothesis only in the long run. This is similar to the result of Bölük and Mert (2015) after employing the autoregressive distributed lag (ARDL) method in the context of Turkey from 1960 to 2010. The findings showed that the EKC hypothesis holds. Additionally, Al-Mulali et al. (2016) have also discovered evidence corroborating the notion of the EKC hypothesis in Kenya employing the period 1980-2012. In another study, Saboori et al. (2012) unveiled the EKC hypothesis in Malaysia using the data on real per capita income and per capita $\mathrm{CO}_{2}$ emissions for the 1980-2010 period. Engaging the ARDL estimation method, findings revealed that income has an inverted U-shaped association with pollution.

Nevertheless, the literature also contains an abundance of studies that have failed to discover empirical evidence in support of this hypothesis. For instance, Amri (2018) measured the linkage of GDP and quadratic GDP with $\mathrm{CO}_{2}$ emissions in Tunisia from 1975 to 2014 using ARDL-breakpoint methods. The empirical evidence has rejected the EKC hypothesis in Tunisia. Likewise, Liu et al. (2017) investigated the EKC hypothesis in the selected four ASEAN countries during the 1970-2013 period. They found that an inverted U-shaped EKC has not existed in the long run. In another study on five ASEAN countries, Kisswani et al. (2018) examined the validity of the EKC hypothesis over the 1971-2013 period by employing ARDL techniques. The empirical investigation has shown that only in Thailand does the validity of the EKC holds. However, this is contrary to the findings of Baek (2015) who examined the non-linear relationship between income and $\mathrm{CO}_{2}$ emissions in Arctic countries from 1960 to 2010 period. The outcome indicated a decline in the $\mathrm{CO}_{2}$ emissions as economic growth increases to a certain higher level. Conclusively, it is observed that the findings of the previous studies are mixed, indicating that further estimation of the EKC hypothesis is inevitable with the use of different pollutants and particularly in the rapidly developing countries, which have attained substantial economic growth and observed rampant environmental degradation concurrently. Hence, these contrasting outcomes demonstrate a need to further investigate the EKC hypothesis for different pollutants and using improved estimation methods.

\section{Data source and empirical procedure}

\subsection{Data and scope}

This study measures the influence of economic growth, energy consumption and trade openness on the environmental pollution proxied by the $\mathrm{CH}_{4}$ emission in the six ASEAN countries from 1985 to 2012. It is worth noting that the data available for $\mathrm{CH}_{4}$ emission determines the selected countries for the study. Table 1 shows the variables description, measurement, symbols used for variables and a priori expectations, while the descriptive statistics of the data are shown in Table 2.

\begin{tabular}{|c|c|c|c|}
\hline Variable name & Symbol & Measurement & a priori \\
\hline Methane & Meth & Methane emissions (kt of $\mathrm{CO}_{2}$ equivalent) & Not applicable \\
\hline GDP per capita & GDP & $\begin{array}{l}\text { GDP per capita (constant } 2010 \text { US\$) is the proxy for } \\
\text { economic growth }\end{array}$ & $\begin{array}{l}\text { Inverted } \\
U \text {-shape }\end{array}$ \\
\hline $\begin{array}{l}\text { Energy } \\
\text { consumption }\end{array}$ & $\mathrm{EC}$ & Energy use (kg of oil equivalent per capita) & Positive \\
\hline Trade openness & TOP & Trade (as \% GDP) & Positive \\
\hline
\end{tabular}

Economic growth and methane emission

\section{$\longrightarrow$}


3.2.1 Test for stationarity. It is important to ascertain the order of integration of the variables before embarking on empirical analysis. To do this, the study employs three efficient unit root tests, namely Im et al. (2003), Fisher-type augmented Dickey-Fuller (ADF) (Maddala and Wu, 1999) and Phillip-Peron (PP). For individual unit root test procedures, autoregressive coefficients are allowed to differ across the cross-sections while panel unit root test results are obtained by merging the individual unit root tests. The null hypothesis of those tests is $H_{0}: \rho_{i}=1$, indicating the existence of a unit root, and the alternate hypothesis is stated as $H_{1}: \rho_{i}<1$.

The Im-Pesaran-Shin (IPS) panel unit root test is appropriate for a dynamic heterogeneous panel that is constructed on the average of the statistics of the individual unit root. The standardized $T$-bar test statistics proposed by the IPS test depends on average $\mathrm{ADF}$ statistics across the cross-sections. This unit root test is quite appropriate for the panel data when time is fixed and $N \rightarrow \sigma$. The IPS test also eliminates a serial correlation problem and is efficient for small size data. IPS uses the following equation for estimation:

$$
\Delta X_{i, t}=\vartheta_{i}+\gamma_{i} X_{i, t-1}+\sum_{j=1}^{k} \varphi_{i} \Delta X_{i, t-j}+\epsilon_{i, t} \quad i=1,2,3 \ldots, N ; t=1,2,3 \ldots, T
$$

In equation [1], $X_{i, t}$ indicates the variable under analysis, $\vartheta_{i}$ shows the individual fixed effects whereas $\gamma_{i}$ produces uncorrelated residuals. The basis of the IPS test similar to that of ADF procedure is stated as follows:

$$
t^{\prime}=\frac{1}{N} \sum_{i=1}^{N} t_{p i}
$$

Maddala and Wu (1999) by following Fisher (1932) and Gonzalo (1994) developed the nonparametric test procedure that permits maximum heterogeneity across cross-sections:

$$
P=-2 \sum_{1=i}^{n} \ln P_{i}
$$

In equation [2], $N$ indicates the cross-sections and $P_{i}$ shows the asymptotic $p$-value of a unit root test for cross-section $i$.

3.2.2 Estimation of PMG and $M G$. To evaluate the EKC, this study employs the (PMG estimation technique developed by Pesaran et al. (1999). There are three issues related to PMG estimation, which are quite essential to discuss before proceeding to estimation. First, it is important to observe the stationarity properties of panel data. Kim et al. (2010) argue that PMG estimators are efficient in the case of a unique co-integration vector explaining the longrun link between the explained and explanatory variables. Similar to the conventional ARDL approach, the PMG estimators are efficient when series are integrated at $I(0), I(1)$ or a blend of

Table 2.

Descriptive statistics

\begin{tabular}{lcccc}
\hline Variable & Meth & GDP & EC & TOP \\
\hline Mean & 87775.97 & 7909.71 & 1564.95 & 143.66 \\
Median & 57219.30 & 2686.06 & 794.41 & 104.72 \\
Maximum & 9128,57 & 50102.23 & 7370.65 & 437.32 \\
Minimum & 843.80 & 384.82 & 260.79 & 18.95 \\
Std. Dev. & 109149.4 & 11888.65 & 1615.37 & 105.24 \\
Observations & 168 & 168 & 168 & 168 \\
\hline
\end{tabular}


both but none should be integrated at order two or above. Second, variables should be cointegrated and PMG uses an error correction term (that must be significant, less than unity and negative) to confirm the presence of co-integration among the variables. Third, PMG estimators are efficient when the long-run coefficients are homogenous across the crosssections (see Baek, 2016; Ibrahim and Raji, 2018).

Also, since the number of groups is less than the time dimension of the data, i.e. $N<T$, the PMG and MG estimators are intermediate approaches for estimating heterogeneous panels of this nature. Given that the countries in the data are within the same regional economic bloc, the assumption of a homogeneous long-run estimate is plausible as these countries may be bonded by the same trade terms, laws, monetary policy inter alia, while the short-run estimates will differ due to country-specific economic and institutional differences. Equation [4] shown below indicates the long-run association among variables as in the ARDL $(p, q, \ldots, q)$ format, to estimate the long-run coefficients and to establish the adjustment's speed to long-run as suggested by Pesaran et al. (1999). To analyze the EKC hypothesis of the increasing impact of economic growth on the $\mathrm{CH}_{4}$ emission, variables are in natural logarithms $(\ln )$ to address the issue of normality, heteroscedasticity, outliers, multicollinearity and to create an elasticity relationship. The empirical model is stated as follows:

$$
\ln \text { Meth }_{i t}=\alpha_{0}+\alpha_{1} \ln G D P_{i t}+\alpha_{2} \ln G D P_{i t}^{2}+\alpha_{3} \ln E C_{i t}+\alpha_{4} T O P_{i t}+\varepsilon_{i t}
$$

where, $\ln M e t h$ is the dependent variable, $\mathrm{CH}_{4}$ emission; $\ln G D P$ is the gross domestic product, and its square is given as $\ln G D P^{2}$; energy consumption is $\ln E C$, and $T O P$ is trade openness. As described by Pesaran et al. (1999), the ARDL representation of equation [4] is given as follows:

$$
\ln \operatorname{Meth}_{i t}=\omega_{i}\left(\ln M e t h_{t-1}-\gamma_{0 i}-\gamma_{i}^{\prime} Z_{i t}\right)+\sum_{j=1}^{p-1} \varphi_{i j}^{*} \Delta \ln M e t h_{i, t-j}+\sum_{j=0}^{q} \delta_{i j}^{* \prime} \Delta Z_{i, t-j}+\mu_{i}+\varepsilon_{i t}
$$

where, $\ln M e t h_{i t}$ is the natural logarithm of the dependent variable, $\Delta$ is the difference operator; $\omega_{i}=-\left(1-\sum_{j=1}^{p} \varphi_{i j}\right) ; \gamma_{i}=-\left(\sum_{j=0}^{q} \delta_{i j} / \omega_{i}\right) ; \varphi^{*} i j=-\sum_{m=j+1}^{p} \varphi_{i m}$ and $j=1,2,3, \ldots, p-1 ; \delta^{* \prime}$ $=-\sum_{m=j+1}^{q} \delta_{i m}$ and $j=1,2,3, \ldots, q-1 ; Z_{i, t}$ indicates the regressors, $\mu_{i}$ is the individual fixed effects and $\varepsilon_{i t}$ is independently distributed across each cross-section having a zero mean and constant variance. It is expected that $\omega_{i}<0$ and statistically significant to establish the longrun association between $\mathrm{CH}_{4}$ emission and the regressors, but if it is non-zero or positive, then the model is explosive and does not converge in the long run (Adeleye et al., 2018). Fulfilling this condition affirms that a long-run relationship (dynamic stability) exists and necessitates the adjustment term's coefficient to be $<0$ but not lower than -2 (that is, within the unit circle).

In the absence of $\varepsilon_{i t}$, equation [5] adjusts to the standard error correction term (ECM) that uses long-run or co-integrating association (indicated by lagged ECM) as a constraint to provide short-run dynamics. The short-run influence of each explanatory variable is measured by the difference terms $(\Delta)$, with lag length $p$ selected by using the AIC (Akaike information criteria). The long-term impacts are indicated by the amalgamation of level variables in the first term (employed as a proxy for a lagged ECM) in equation [5], $\gamma_{i}$ shows the vector of corresponding long-run co-efficient and $\omega_{i}$ estimates the adjustment's speed of explained variable, $\ln M e t h_{\text {it }}$ towards its long-run equilibrium with respect to change in explanatory variables. This study also uses MG estimation put forward by Pesaran and Smith (1995) to estimate equation [5], as an alternative estimation to PMG. MG estimators estimate the time series of each cross-section and take the mean of coefficients while the PMG estimator pooled all the coefficients. Furthermore, Hausman's test decides between the use of

\section{Economic growth and methane emission}


the MG and PMG estimators as the most appropriate technique to adopt. That is, if the $p$-value of the Hausman test is statistically not significant $(\phi>0.5)$, then PMG is the best option for estimation: otherwise, the MG estimator will be used.

\section{Empirical findings and discussion}

\subsection{Empirical findings}

The analysis of the current study begins with the testing of a unit root in the variables, and the outcomes of which are shown in Table 3. The findings in Table 3 exhibit that the $\mathrm{CH}_{4}$ emission is stationary at a level while explanatory variables, namely GDP, EC and TOP are stationary at the first difference. Hence, this mixed unit root results justify the use of the dynamic panel ARDL estimation technique.

Having established the stationarity of the variables, we proceed to analyze the model using the PMG estimator. The outcome of the Hausman' test with the p-value of 0.6257 justifies the use of the PMG estimator. Table 4 presents the outcomes obtained through PMG estimators.

The results in Table 4 indicate that the EKC hypothesis for $\mathrm{CH}_{4}$ emission holds in the long run for the six selected ASEAN countries over the period under consideration. Findings reveal a non-linear and inverted U-shaped relationship. For instance, the coefficient of per capita GDP is positive and statistically significant at the $1 \%$ significance level. That is a percentage change in economic growth causes $\mathrm{CH}_{4}$ emissions to increase by $6.5 \%$, on average, ceteris paribus. It shows that at the initial stages of economic growth $\mathrm{CH}_{4}$ emission increases. However, as economic growth increases further, the $\mathrm{CH}_{4}$ emissions (pollution) begins to decrease as argued by the EKC hypothesis. This is evident by the negative coefficient of the squared of GDP per capita $(-0.38)$ which is statistically significant at the $1 \%$

\begin{tabular}{llllll}
\hline Variables & & Meth & GDP & EC & TOP \\
\hline IPS & L_variable & $0.01^{* *}$ & 0.32 & 0.84 & 0.73 \\
& D_variable & - & $0.00^{* *}$ & $0.00^{* *}$ & $0.00^{* *}$ \\
ADF-Fisher & L_variable & $0.03^{* *}$ & 0.28 & 0.90 & 0.40 \\
& D_variable & - & $0.00^{* *}$ & $0.00^{* *}$ & $0.00^{* *}$ \\
PP-Fisher & L_variable & $0.00^{* *}$ & 0.46 & 0.98 & 0.38 \\
& D_variable & - & $0.00^{* *}$ & $0.00^{* *}$ & $0.00^{* *}$ \\
Decision & & $I(0)$ & $I(1)$ & $I(1)$ & $I(1)$
\end{tabular}

Table 3. Note(s): * and ** are significant levels at 1 and $5 \%$, respectively; variables are in natural logarithms. Unit root test results L_variable and D_variable indicate the level variable and one time differenced variable, respectively

Results of pooled mean group (PMG) estimation
Dependent variable: Methane emission

Variables

Long run

Short run

GDP

$\mathrm{GDP}^{2}$

EC

$6.54 *(0.00)$

$-0.38 *(0.00)$

$0.71^{*}(0.00)$

TOP

$-0.0006(0.231)$

$43.15(0.31)$

$-2.80(0.30)$

$-0.57(0.16)$

$0.00(0.19)$

$-0.46^{* *}(0.03)$

Hausman statistic $=2.61(0.6257)$

Note(s): * and ** show significant levels at 1 and $5 \%$, respectively; $p$-values are in parentheses 
level. This gives evidence that economic growth has an inverted U-shaped and non-linear associations with pollution. Hence, the EKC hypothesis in this study for the selected ASEAN economies holds. Furthermore, from the two control variables, energy consumption exerts a significant and positive impact on the $\mathrm{CH}_{4}$ emission at the $1 \%$ level. That is, a percentage change in energy consumption is associated with an increase in the $\mathrm{CH}_{4}$ emission by $0.71 \%$, on average, ceteris paribus. It indicates that energy consumption is also a central source of the $\mathrm{CH}_{4}$ emission in the selected ASEAN countries. Nevertheless, trade openness is empirically discovered to be insignificant in this study. Lastly, the adjustment coefficient of -0.46 suggests that the previous year's errors are corrected in the current year at a speed of $46 \%$.

This study uses the MG estimator put forwarded by Pesaran and Smith (1995) as an alternative method in dynamic panel model analysis. The MG and PMG estimators differ in the former estimate time series regression individually for each cross-section and then obtain the mean values of the coefficients. Contrarily, as indicated in Table 5, the MG technique provides no evidence for the EKC hypothesis. Nevertheless, the relation between energy consumption and $\mathrm{CH}_{4}$ pollution is statistically significant at the $5 \%$ level both in the long and short runs, howbeit with asymmetric impacts.

\subsection{Discussion}

Similar to $\mathrm{CO}_{2}$ emissions, $\mathrm{CH}_{4}$ dioxide is also contributing substantially to climate change and causing various socio-economic challenges. Therefore, the current study tests the EKC hypothesis by using $\mathrm{CH}_{4}$ emissions as a pollutant in the context of the six selected ASEAN countries.

The findings of the study exhibit that the EKC hypothesis holds for the selected ASEAN countries. Meaning that, at the initial stages of economic growth, the $\mathrm{CH}_{4}$ emission increases in these economies. Nevertheless, at the advanced stages of economic growth, the $\mathrm{CH} 4$ emissions begin to decline. It shows that economic growth is essential to reduce $\mathrm{CH}_{4}$ emissions and ameliorate environmental quality. Further, this validation of the EKC hypothesis demonstrates that these ASEAN countries are accumulating economic growth through environmentally sustainable means. This outcome supports previous findings for the ASEAN countries (see, for instance, Nasir et al., 2019; Phong, 2019; Saboori et al., 2012; Shahbaz et al., 2019). However, the finding of this study is contrary to the studies of Zoundi (2017) and Mert and Bölük (2016), which have found that increase in per capita income causes pollution to increase further. It is also worthy to discuss here that the above-mentioned studies have employed $\mathrm{CO}_{2}$ emissions while testing the EKC hypothesis for the ASEAN countries. Nonetheless, the current study is novel as it tests the EKC hypothesis by using $\mathrm{CH}_{4}$ emissions for the selected ASEAN countries.

Likewise, energy consumption is discovered to be another vital factor responsible for enhancing $\mathrm{CH}_{4}$ emissions in the selected ASEAN countries. Since 2000, ASEAN countries have experienced $80 \%$ surge in energy demand and a substantial portion of this energy demand has been provided through the combustion of fossil fuels such as coal and oil

\begin{tabular}{lcc}
\hline Dependent variable: Methane emission & & \\
Variables & Long run & Short run \\
\hline GDP & $9.94(0.32)$ & $-2.09(0.81)$ \\
GDP $^{2}$ & $-0.58(0.37)$ & $0.06(0.90)$ \\
EC & $0.39^{* *}(0.02)$ & $-0.52^{* *}(0.07)$ \\
TOP & $-0.00(0.38)$ & $0.00(0.29)$ \\
Adjustment term & & $-0.66^{*}(0.00)$
\end{tabular}

Note(s): * and ** show significant levels at 1 and $5 \%$ respectively; $p$-values are in parentheses

\section{Economic growth and methane emission}


(IEA, 2019). As a consequence, energy consumption in these countries is extensively contributing to the $\mathrm{CH}_{4}$ dioxide and therefore lowering the air quality. This outcome is in line with the findings of previous studies examining the effects of energy consumption on $\mathrm{CH}_{4}$ emissions (Adeel-Farooq et al., 2018; Bakar et al., 2019; Yahaya et al., 2020; Wang et al., 2016).

\section{Conclusion}

This study examines the consequences of GDP, a quadratic form of GDP and two controlled variables, namely energy consumption and trade openness on $\mathrm{CH}_{4}$ emissions by using the EKC hypothesis framework in six ASEAN countries. For estimation, dynamic panel data methods such as MG and PMG have been employed. The outcomes of the study verify the EKC hypothesis in these economies. It means that economic growth as argued by the EKC hypothesis, after attaining a certain higher level reduces the pollution $\left(\mathrm{CH}_{4}\right.$ emission) in the long run. Additionally, energy consumption is empirically found to have a positive relationship with $\mathrm{CH}_{4}$ emissions in these ASEAN countries. However, trade openness is discovered to have an insignificant association with $\mathrm{CH}_{4}$ emissions.

Although, $\mathrm{CH}_{4}$ emission in the selected ASEAN countries is observed to be declining with an increase in economic growth. Nevertheless, efficient and urgent policies are needed in these countries to bring an extensive and prompt decline in the $\mathrm{CH}_{4}$ emission levels to drastically halt the process of climate change. Evidence reveals that these countries are highly vulnerable to climate change; therefore, policymakers are enjoined to formulate policies that will help to mitigate the $\mathrm{CH}_{4}$ emission extensively in the atmosphere. In addition, these six countries should promote the use of renewable energy rather than fossil fuel-based energy in the industrial sector and transportation as well. Moreover, policies should be designed to enhance the pace of economic growth as it has empirically been observed as a remedy for the environmental challenges in these countries. Nevertheless, advance, energyefficient and pro-environment technologies should be utilized in the manufacturing sector too in order to accelerate the economic growth and ameliorate the environmental quality simultaneously. Lastly, the governments of these ASEAN countries through proper legislation and implementation should address environmental challenges, so that SDGs could be achieved within the stipulated time frame.

\section{References}

ADB (2015), "Southeast Asia and the economics of global climate stabilization", available at: https:// www.adb.org/sites/default/files/publication/178615/sea-economics-global-climate-stabilization.pdf.

Adeel-Farooq, R.M., Bakar, N.A.A. and Raji, J.O. (2018), "Greenfield investment and environmental performance: a case of selected nine developing countries of Asia", Environmental Progress and Sustainable Energy, Vol. 37, pp. 1085-1092.

Adeleye, N., Osabuohien, E., Bowale, E., Matthew, O. and Oduntan, E. (2018), "Financial reforms and credit growth in Nigeria: empirical insights from ARDL and ECM techniques", International Review of Applied Economics, Vol. 32 No. 6, pp. 807-820.

Al-Mulali, U., Saboori, B. and Ozturk, I. (2015a), "Investigating the environmental Kuznets curve hypothesis in vietnam", Energy Policy, Vol. 76, pp. 123-131.

Al-Mulali, U., Weng-Wai, C., Sheau-Ting, L. and Mohammed, A.H. (2015b), "Investigating the environmental Kuznets curve (EKC) hypothesis by utilizing the ecological footprint as an indicator of environmental degradation”, Ecological Indicators, Vol. 48, pp. 315-323.

Al-Mulali, U., Solarin, S.A. and Ozturk, I. (2016), "Investigating the presence of the environmental Kuznets curve (EKC) hypothesis in Kenya: an autoregressive distributed lag (ARDL) approach", Natural Hazards, Vol. 80 No. 3, pp. 1729-1747. 
Amri, F. (2018), "Carbon dioxide emissions, total factor productivity, ICT, trade, financial development, and energy consumption: testing environmental Kuznets curve hypothesis for Tunisia", Environmental Science and Pollution Research, Vol. 25 No. 33, pp. 33691-33701.

Baek, J. (2015), "Environmental Kuznets curve for $\mathrm{CO}_{2}$ emissions: the case of Arctic countries", Energy Economics, Vol. 50, pp. 13-17.

Baek, J. (2016), "Short communication A new look at the FDI - income - energy - environment nexus: dynamic panel data analysis of ASEAN”, Energy Policy, Vol. 91, pp. 22-27.

Bakar, N.A.A., Raji, J.O. and Adeel-Farooq, R.M. (2019), "Greenfield, mergers and acquisitions, energy consumption, and environmental performance in selected SAARC and ASEAN countries", International Journal of Energy Economics and Policy, Vol. 9 No. 2, pp. 216-224.

Beckerman, W. (1992), "Economic growth and the environment: whose growth? Whose environment?", World Development, Vol. 20, pp. 481-496.

Bhattarai, M. and Hammig, M. (2001), "Institutions and the environmental Kuznets curve for deforestation: a crosscountry analysis for", World Development, Vol. 29 No. 6, pp. 995-1010.

Bilgili, F., Koçak, E. and Bulut, Ü. (2016), "The dynamic impact of renewable energy consumption on $\mathrm{CO}_{2}$ emissions: a revisited Environmental Kuznets Curve approach", Renewable and Sustainable Energy Reviews, Vol. 54, pp. 838-845.

Bölük, G. and Mert, M. (2015), "The renewable energy, growth and environmental Kuznets curve in Turkey: an ARDL approach", Renewable and Sustainable Energy Reviews, Vol. 52, pp. 587-595.

Borhan, H., Ahmed, E.M. and Hitam, M. (2018), " $\mathrm{CO}_{2}$, quality of life and economic growth in ASEAN 8", Journal of ASIAN Behavioural Studies, Vol. 3 No. 6, p. 55.

Cole, M.A. (2004), "Trade, the pollution haven hypothesis and the environmental Kuznets curve: examining the linkages", Ecological Economics, Vol. 48 No. 1, pp. 71-81.

Fisher, R. (1932), Statistical Methods for Research Workers, Oliver and Boyd, London.

Gonzalo, J. (1994), "Five alternative methods of estimating long-run equilibrium relationships", Journal of Econometrics, Vol. 60 Nos 1-2, pp. 203-233.

Grossman, G.M. and Krueger, A.B. (1991), Environmental impacts of a North American Free Trade Agreement, National Bureau of Economic Research Working Paper Series.

Ibrahim, Y. and Raji, J.O. (2018), "Cross-border merger and acquisition activities in Asia: the role of macroeconomic factors", Studies in Economics and Finance, Vol. 35 No. 2, pp. 307-329.

IBRD (1992), Development and the Environment, available at: https:/openknowledge.worldbank.org/ handle/10986/5975.

IEA (2019), Southeast Asia Energy Outlook 2019, IEA, Paris, available at: https:/www.iea.org/reports/ southeast-asia-energy-outlook-2019.

Im, K.S., Pesaran, M.H. and Shin, Y. (2003), “Testing for unit roots in heterogeneous panels”, Journal of Econometrics, Vol. 115, pp. 53-74.

IPCC (2014), Climate Change 2014 Synthesis Report, available at: https://www.ipcc.ch/site/assets/ uploads/2018/05/SYR_AR5_FINAL_full_wcover.pdf.

Jalil, A. and Mahmud, S.F. (2009), "Environment Kuznets curve for $\mathrm{CO}_{2}$ emissions: a cointegration analysis for China”, Energy Policy, Vol. 37 No. 12, pp. 5167-5172.

Janardanan, R., Maksyutov, S., Ito, A., Yukio, Y. and Matsunaga, T. (2017), "Assessment of anthropogenic methane emissions over large regions based on GOSAT observations and high resolution transport modeling", Remote Sensing, Vol. 9 No. 9, pp. 1-11.

Kim, D.H., Lin, S.C. and Suen, Y.B. (2010), "Dynamic effects of trade openness on financial development”, Economic Modelling, Vol. 27 No. 1, pp. 254-261.

Kisswani, K.M., Harraf, A. and Kisswani, A.M. (2018), "Revisiting the environmental kuznets curve hypothesis: evidence from the ASEAN-5 countries with structural breaks", Applied Economics, Vol. 51 No. 17, pp. 1855-1868. 
Liu, X., Zhang, S. and Bae, J. (2017), "The impact of renewable energy and agriculture on carbon dioxide emissions: investigating the environmental Kuznets curve in four selected ASEAN countries", Journal of Cleaner Production, Vol. 164 No. 2017, pp. 1239-1247.

López-Menéndez, A.J., Pérez, R. and Moreno, B. (2014), "Environmental costs and renewable energy: Re-visiting the environmental Kuznets curve", Journal of Environmental Management, Vol. 145, pp. 368-373.

Maddala, G.S. and Wu, S. (1999), "A comparative study of unit root tests with panel data and a new simpletest”, Oxford Bulletin of Economics and Statistics, Vol. 61, pp. 631-652.

Meadows, D.H., Meadows, D.L., Randers, J. and Behrens, W. (1972), The Limits to Growth, Universe Books, New York, NY.

Mert, M. and Bölük, G. (2016), "Do foreign direct investment and renewable energy consumption affect the $\mathrm{CO}_{2}$ emissions? New evidence from a panel ARDL approach to Kyoto Annex countries", Environmental Science and Pollution Research, Vol. 23, pp. 21669-21681.

Nasir, M.A., Duc Huynh, T.L. and Xuan Tram, H.T. (2019), "Role of financial development, economic growth and foreign direct investment in driving climate change: a case of emerging ASEAN", Journal of Environmental Management, Vol. 242, March, pp. 131-141.

Panayotou, T. (1993), "Empirical tests and policy analysis of environmental degradation at different stages of economic development by", available at: http://www.ilo.org/public/libdoc/ilo/1993/ 93B09_31_engl.pdf.

Pesaran, M.H. and Smith, R.P. (1995), "Estimating long-run relationships from dynamic heterogeneous panels", Econometrics, Vol. 68 No. 1, pp. 79-113.

Pesaran, M.H., Shin, Y. and Smith, R.P. (1999), "Pooled mean group estimation of dynamic heterogenous panels", American Statistical Association, Vol. 94 No. 446, pp. 621-634.

Phong, L.H. (2019), "Globalization , financial development, and environmental degradation in the presence of environmental Kuznets Curve: evidence from ASEAN-5 countries", International Journal of Energy Economics and Policy, Vol. 9 No. 2, pp. 40-50.

Prakash, A. (2018), "Boiling point”, available at: https://www.imf.org/external/pubs/ft/fandd/2018/09/ pdf/southeast-asia-climate-change-and-greenhouse-gas-emissions-prakash.pd.

Saboori, B., Sulaiman, J. and Mohd, S. (2012), "Economic growth and $\mathrm{CO}_{2}$ emissions in Malaysia: a cointegration analysis of the Environmental Kuznets Curve", Energy Policy, Vol. 51, pp. 184-191.

Saeidpour, L., Heidari, H. and Katirciog, S.T. (2015), "Electrical Power and Energy Systems Economic growth , $\mathrm{CO}_{2}$ emissions , and energy consumption in the five ASEAN countries", Electrical Power and Energy Systems, Vol. 64, pp. 785-791.

Shahbaz, M., Haouas, I. and Van Hoang, T.H. (2019), "Economic growth and environmental degradation in vietnam is the environmental kuznets curve a complete picture?", Emerging Markets Review, Vol. 38, pp. 197-218.

Stern, D.I. (1998), "Progress on the environmental Kuznets curve?", Environment and Development Economics, Vol. 3 No. 2, pp. 173-196.

UNEP (2019), "Emerging issues of environmental concern", United Nations Environment Programme, available at: https:/web.unep.org/frontiers/sites/unep.org.frontiers/files/documents/unep_ frontiers_2016.pdf.

Wang, S., Li, Q., Fang, C. and Zhou, C. (2016), "The relationship between economic growth, energy consumption, and $\mathrm{CO}_{2}$ emissions: empirical evidence from China", The Science of the Total Environment, Vol. 542, pp. 360-371.

Yahaya, N.S., Mohd-Jali, M.R. and Raji, J.O. (2020), "The role of financial development and corruption in environmental degradation of Sub-Saharan African countries", Management of Environmental Quality: An International Journal, Vol. 31, pp. 895-913. 
Yusuf, R.O., Noor, Z.Z., Abba, A.H., Hassan, M.A.A. and Din, M.F.M. (2012), "Methane emission by sectors: a comprehensive review of emission sources and mitigation methods", Renewable and Sustainable Energy Reviews, Vol. 16 No. 7, pp. 5059-5070.

Zoundi, Z. (2017), " $\mathrm{CO}_{2}$ emissions , renewable energy and the Environmental Kuznets Curve, a panel cointegration approach", Renewable and Sustainable Energy Reviews, Vol. 72, November 2016, pp. 1067-1075.

\section{Further reading}

Blackburne, E.F. III and Frank, M.W. (2007), "Estimation of nonstationary heterogeneous panels", STATA Journal, Vol. 7 No. 2, pp. 197-208.

Loayza, N. and Rancière, R. (2004), Financial Development, Financial Fragility and Growth, Policy Research Working Paper; No. 3431, World Bank, Washington, DC, pp. 1-35.

Pesaran, M.H., Shin, Y. and Smith, R.P. (1997), Estimating Long-Run Relationships in Dynamic Heterogeneous Panels, DAE Working Papers, Amalgamated Series 9721.

Pesaran, M.H. (2004), "General diagnostic tests for cross section dependence in panels", Journal of Econometrics, Vol. 69 No. 7, pp. 1-39.

Pesaran, M.H. (2007), "A simple panel unit root test in the presence of cross-section dependence", Journal of Applied Econometrics, Vol. 22, pp. 265-312, doi: 10.1080/07474938.201.

Raji, J.O., Ibrahim, Y. and Ahmad, S.A. (2017), "Stock price index and exchange rate nexus in African markets", International Economic Journal, Vol. 31 No. 1, pp. 112-134.

Samargandi, N., Fidrmuc, J. and Ghosh, S. (2013), Is the Relationship between Financial Development and Economic Growth Monotonic for Middle-Income Countries?, Working Paper No. 13-21, Brunel University, Department of Economics and Finance, pp. 1-52.

Westerlund, J. (2007), "Testing for error correction in panel data", Oxford Bulletin of Economics and Statistics, Vol. 69, pp. 709-748.

Yamarik, S., El-Shagi, M. and Yamashiro, G. (2016), "Does inequality lead to credit growth? Testing the rajan hypothesis using state-level data", Economics Letters, Vol. 148, pp. 63-67.

\section{Corresponding author}

Rana Muhammad Adeel-Farooq can be contacted at: adeelr333@gmail.com, adeel@uosahiwal.edu.pk

For instructions on how to order reprints of this article, please visit our website:

www.emeraldgrouppublishing.com/licensing/reprints.htm

Or contact us for further details: permissions@emeraldinsight.com 